\title{
Study of adsorption of imidacloprid onto two different textures of soils
}

\author{
Yao Urbain KOUAKOU ${ }^{1 *}$, Ardjouma DEMBELE ${ }^{2}$, Aimé Serge ELLO ${ }^{1}$, \\ Yapi Serge BROU ${ }^{1}$, Brou Lazare YAO $^{2}$ and Albert TROKOUREY ${ }^{1^{*}}$ \\ ${ }^{I}$ UFR SSMT, Laboratoire de Chimie Physique, Université Félix Houphouët-Boigny, 22 BP 582 Abidjan 22, Côte d'Ivoire. \\ ${ }^{2}$ Laboratoire Central d'Agrochimie et d'Ecotoxicologie (LCAE), Abidjan, Côte d'Ivoire. \\ "Corresponding author, E-mail: urbainyk@gmail.com, 21 BP 1639 Abidjan 21 Côte d'Ivoire. Tel.: +225 08019697
}

\begin{abstract}
The main goal of this research is to evaluate the potential for imidacloprid to contaminate water and ground water. For this purpose, the adsorption of imidacloprid on two different soils is investigated. Physicochemical properties such as texture, organic matter, $\mathrm{pH}$ of the two soils are investigated. Both soils have high organic matter and the same $\mathrm{pH}$ but different textures. The kinetic study of adsorption on these soils over 90 days yielded a mean half-life of 60 days. Furthermore, adsorption kinetics of imidacloprid was studied and the rate of sorption was found to conform to pseudo-second-order kinetics with $3.10 \mathrm{mg} / \mathrm{g} / \mathrm{h}$ and 10.204 $\mathrm{mg} / \mathrm{g} / \mathrm{h}$ for soils of banana field and cocoa field respectively. Equilibrium isotherm data were analyzed according to Langmuir, Freundlich and Redlich-Peterson equations. The Redlich-Peterson isotherm gave the best correlation for the adsorption of imidacloprid adsorption on soils. The maximum adsorption capacities were determined to be $4.139 \mathrm{mg} / \mathrm{g}$ and $5.74 \mathrm{mg} / \mathrm{g}$ of soils from banana field and cocoa field respectively.The differences in adsorption capacities may be due to the effect of soils textures.
\end{abstract}

(C) 2015 International Formulae Group. All rights reserved.

Keywords: Imidacloprid, soils textures, adsorption, Redlich-Peterson model, Freundlich model, HPLC.

\section{INTRODUCTION}

Earth is called blue planet because it contains $72 \%$ of water, or 1,360 billion $\mathrm{km}^{3}$. However, only $2.3 \%$ is fresh water available for human needs. Almost all of this freshwater is in ground and basement and, a small percentage in lakes, marshes, atmosphere and water courses (Perrier et al., 2005). But these resources of water are highly threatened by pollution of all kinds of species, especially pesticides. Although pesticides are known to increase production yields, protect food supply, protect against disease vectors and parasites toxin producers (Ayranci et al., 2004; Carvalho, 2006; FAO, 2012). The population growth in contradiction with the needs of human being or the surfaces of available arable land increases more and more the use of pesticides. Unfortunately, once ejected, pesticides undergo several physical, biological and chemical process including volatilization, infiltration, retention and degradation which can be harmful to the environment. It is estimated that during spraying pesticides, 25 to $75 \%$ is waste in the atmosphere, leading to the contamination of the air, mist and rain. A significant fraction streams then infiltrate to reach and contaminate the surface water and the ground water (Margni et al., 2002). Even, some 
pesticides can contaminate the food through various mechanisms.

Imidacloprid or 1-(6-chloro-3pyridinylmethyl)-N-nitro-imidazolidin-2-

ylideneamine (Figure 1), like most pesticides, is a systemic insecticide which can spread throughout the body of the plant. This character leads to the presence of these insecticides in the nectar and the pollen of the flowers of treated crops (Bonmatin et al., 2005; Stokstad, 2012). As they are powerful neurotoxic to insects, this kind of diffusing insecticides is unfortunately most used in the world (Charvet, 2004). A recent study about leaching of imidacloprid up to $60 \mathrm{~cm}$ depth showed that its concentration decreased with depth (Muhammad et al., 2012). However, according to a report from the Ministry of Environment of Quebec, imidacloprid was detected in $35 \%$ of groundwater samples collected near potato crops (Giroux, 2003). Moreover, it is very stable in water and hardly degradable in the $\mathrm{pH}$ range between 4 and 9 . This character leads to its classification as persistent in Soil by ARP (Agency Regulation of Pest). According to Canadian council of the environmental minister (CCEM), the half-life typical $\mathrm{DT}_{50}$ of imidacloprid is estimated to be 40 days to 2 years (CCEM, 2007.). Furthermore, the adsorption is one of the important phenomena in the process of degradation, which itself depends on several parameters such as physico-chemical properties of the soil, the contact time and the method used to assess the adsorption. The mobility of imidacloprid in soil, taking account the $\mathrm{pH}$, or the structure of the soil has been the subject of extensive investigation (Sabbagh et al., 2002; Papiernik et al., 2006). However, no work on the influence of the soil type on the adsorption of imidacloprid has been conducted yet. The present work aims at studying the adsorption of imidacloprid on two different textures of soil, mainly in order to know the favorable soil for the degradation of imidacloprid. For this, we used a fast reliable and inexpensive extraction method based on solid-liquid extraction. This study is important in order to minimize the risk of water contamination for country such as Ivory
Coast (Côte d'Ivoire), where imidacloprid constitutes more than $50 \%$ of insecticide used in agriculture (MINAGRI, 2012).

\section{MATERIALS AND METHODS Materials}

Imidacloprid standard high purity (98\%) was provided by Dr. Ehrenstorfer GmbH (Germany) and used to have calibration data for HPLC analysis and Commercial imidacloprid solution called CAO-NET $30 \mathrm{SC}$ with concentration $30 \mathrm{~g} / \mathrm{L}$ manufactured by SOFACO AF- CHEM purchased from local market ( Abidjan, Côte d'Ivoire) used as pesticide which will be study. The concentration of imidaclopid was analyzed using on HPLC system Shimadzu Prominence LC-20A series equipped with UV-Vis detector SPD -20 A (set on $252 \mathrm{~nm}$ ), Shimadzu interchrom ODS C18 (250 x 4.6 $\mathrm{mm}$ ) and a computer system to check solvent gradient. Sieves with different pores for soil texture, a muffle furnace (Nabertherm West Germany) preheated to the $375{ }^{\circ} \mathrm{C}$ for determination of organic matter and a $\mathrm{pH}$ meter (multipara-meter HQ 40d) were also used.

\section{Methods \\ Study Area}

Two types of fields were selected for the study. The first field is used for the cultivation of bananas located in Attinguié, North of Abidjan (soil A) and the second field is for the cultivation of cocoa located in Azaguié, east of Abidjan (soil B). Both fields underwent treatment with imidacloprid.

\section{Simple preparation}

Standards solutions from high purity of imidacloprid and those prepared with commercial solution were prepared following the same simple protocol. Indeed $2 \mathrm{~mL}$ of stock solution were taken and dissolved in distilled water to obtain new solutions at lower concentrations and detectable by high performance liquid chromatography (HPLC) analysis. Acetic acid was used to prepare $0.01 \%$ solution of acetic acid in water for HPLC analysis. The other reagents have not undergone pretreatment. 


\section{Characterization of soils}

For the soil texture, $10 \mathrm{~g}$ of soil were used and separated with different sieves (2 $\mathrm{mm}$, until $0.002 \mathrm{~mm}$ pores). So, the sizes of the soil which sieve are higher than $2 \mathrm{~mm}$ correspond to sand and under $0.002 \mathrm{~mm}$ to clay (Ben Hassine H, 2006). A muffle furnace (Nabertherm West Germany) preheated to the $375{ }^{\circ} \mathrm{C}$ was used to obtain organic matter by Walkley-Black method (Moreno et al., 2001).

\section{Extraction of soil}

The samples from the different soils were dried at room temperature for 48 hours to have total dryness. $10 \mathrm{~g}$ of dry soil were mixed with $20 \mathrm{~mL}$ of acetonitrile in a screw cap tube of $50 \mathrm{~mL}$, and then the mixture is placed on a magnetic agitator for 30 minutes at a speed of $160 \mathrm{rpm}$. After decantation, 10 $\mathrm{mL}$ of the supernatant are transferred to a flask and evaporated to dryness on rotavapor. The residue is taken up in $5 \mathrm{~mL}$ of acetonitrile solution and then analyzed by HPLC to determine the concentration.

\section{Conditions of chromatography analysis}

Mobile phase was acetonitrile $/ 0.01 \%$ acetic acid-water $(40: 60, \mathrm{v} / \mathrm{v})$ at a flow rate of $1.0 \mathrm{~mL} \mathrm{~min}^{-1}$, the volume injected was $20 \mu \mathrm{L}$. The recording of peaks for samples with different surfaces was realized with microprocessor-assisted software SHIMADZU. Under this operating condition, the retention time of imidacloprid was 5.33 min.

\section{Statistical method used}

In this work, the obtained graphs are the average calculated using $\bar{X}=\frac{1}{n} \sum_{i=1}^{n} X_{i}$ (each test is done three times), the standard deviation is obtained from $S D=\sqrt{\frac{1}{n-1}\left(\sum_{i=1}^{n}\left(X_{i}-\bar{X}\right)^{2}\right)}$ and the relative standard deviation is performed by $\mathrm{RSD}=100 \frac{\mathrm{SD}}{\mathrm{X}}$.

Limit of detection (LOD) $=$ $3 \times \mathrm{RSD} \times$ concentration (lowest). The limit of quantification (LOQ) defined as the lowest measured quantity above which the analyte can be quantified was obtained by LOQ $=3.3$ x LOD (Shrivastava, 2011).

\section{RESULTS AND DISCUSSION}

Physicochemical properties of soil

As the physicochemical properties such as $\mathrm{pH}$, texture, organic matter and electrical conductivity of the soil can significantly affect the transfer of the pesticide through the different compartments of environment, these parameters are investigated. The results are shown in Table 1. It can be seen that both soils are acidic. So they would be more favorable for the adsorption of the pesticides such as imidacloprid (Paszko, 2006; Ping, 2010). On the other hand, the values of the organics matters of the soils suggest that the textures of soils can influence adsorption of imidacloprid onto these soils (MadrigalMonarez, 2004). However, the lower electrical conductivity value of these soils indicates that the contact-time of adsorption would be reduced (Muhammad, 2012).The soil of banana field has higher percentage of sand and a bit of clay (2.6\%), but the soil of cocoa field contains an important proportion of clay (18.18). Pesticides could infiltrate the first soil (banana field). As imidacloprid is a polar substance $(\log$ Kow $=0.57)$, it might be retained on soil of cocoa field which has the best proportion of clay and slit (Sheng et al., 2001).

\section{Evolution of imidacloprid on soils Method performance}

The parameters of the extraction method were evaluated. The quality of the extraction is performed by Percent Recovery like this: blank soil of $10 \mathrm{~g}$ weight was spiked with 3 different concentrations $(0.1,0.5$ and 1 $\mathrm{ppm}$ ) of imidacloprid standard solutions. The mixture was vigorously vortexed for 12 hours at a speed of $300 \mathrm{rpm}$ to distribute completely the pesticide. The mixture was dried at room temperature. Then the result of the $10 \mathrm{~g}$ was mixed with $20 \mathrm{~mL}$ of acetonitrile in a screw cap tube of $50 \mathrm{~mL}$, and then the mixture is placed on a magnetic agitator for 30 minutes at a speed of $160 \mathrm{rpm}$. After decantation, 10 $\mathrm{mL}$ of the supernatant are transferred to a flask and evaporated to dryness on rotavapor. The residue is taken up in $5 \mathrm{~mL}$ of acetonitrile solution and then analyzed by HPLC to 
determine the concentration. The recovered percentage of imidacloprid in soil A and B are given in Table 2. The recoveries were found to be $74 \%$ for the soil $\mathrm{A}$ and $81.12 \%$ for the soil B. The percent recovery is higher than $70 \%$. Considering the recent EU guidelines for method validation which mention acceptability criteria of recovery to be between 70 and $120 \%$, these results are in good agreement (Melo et al., 2005; Walorczyk, 2007). So this method could be accepted for imidacloprid extraction onto soils.

Furthermore, the LOD and LOQ are determined and given in Table 2. These values are good and lower than those found by some researchers. LOQ is below imidacloprid MRL estimated to $0.1 \mathrm{mg} / \mathrm{Kg}$ (Concha-Grañan et al., 2010; Pizzutti et al., 2007). Retention time is $5.33 \mathrm{~min}$. All these values show that the extraction and the analysis method of imidacloprid are good.

\section{Residual concentrations of imidacloprid in} soils

The evolution of imidacloprid concentration on the soils is studied. The results are shown in Table 3. As shown, the concentration of imidacloprid decreases slowly. This slow decrease in concentration suggests that the imadacloprid does not adsorb significantly on this soils. However, compared with adsorption of imidacloprid on each soil it seems that the adsorption is better and quicker on the soil $\mathrm{B}$. The calculated $\mathrm{DT}_{50}$ is found to be around 60 days for the soil $\mathrm{B}$ while the $\mathrm{DT}_{50}$ for the soil $\mathrm{A}$ is between 60 and 90 days which are in concordance with the previous work (Sabbagh et al., 2002). This concordance in these results may be due to the pesticide formulation which is SC (Suspension Concentrated) and characteristics of the soils (Sheng et al., 2001; Madrigal-Monarez, 2004; Muhammad et al., 2012). After 90 days, the concentration of imidacloprid in these soils is higher than $0.3 \mathrm{ppm}(\mathrm{mg} / \mathrm{L})$ suggesting that this pesticide is persistent.

\section{Kinetic study of the imidacloprid adsorption}

The study of the kinetics of the imidacloprid adsorption on the soils was carried out at room temperature. For this study, $1 \mathrm{~g}$ of the soil was mixed with $20 \mathrm{ml}$ of
$10 \mathrm{ppm}$ of standard imidacloprid solution in a $100 \mathrm{ml}$ conical flask. These mixtures were shaken on magnetic agitator at $200 \mathrm{rpm}$ for intervals time of $0,0.25,05,0.45,1,2,3,5,6$ and 8 hours. After each contact time, the solutions were filtered and the initial and final concentrations of imidacloprid were determined by HPLC. The amount of imidacloprid adsorbed onto the soil is calculated according to the equation (1):

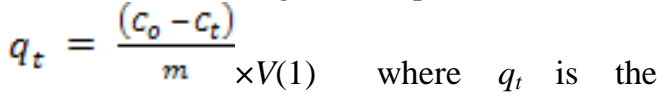
amount of adsorbed imidacloprid on the soil sample $(\mathrm{mg} / \mathrm{g}), C_{0}$ and $C_{t}$ are the initial and the final concentration of imidacloprid at time after filtration $(\mathrm{mg} / \mathrm{L})$ respectively, $V$ is the initial solution volume (L) and $m$ the mass of the soil sample (g).

Figure 2 shows the kinetic adsorption curves. As displayed, a rapid adsorption until 2 hours followed by a slow adsorption and finally reach equilibrium time at 6 hours can be observed. The rapid adsorption of imidacloprid should be due to the vacant sites which are initially available in the soil, while the observed slow adsorption could be due to a slow migration and diffusion of imidacloprid molecules in soil after the saturation of vacant sites (Paszko, 2006).The equilibrium time found is similar to those reported in literature (Kumar et al., 2006; Pizzutti et al., 2007; Muhammad et al., 2012). This behavior does not depend on the type of soil may but be due the fact that both soils contain the same amount of organic matter.

Besides, the curves of Figure 2 are those of pseudo second order model. Regression coefficients higher than 0.99 are obtained. The adsorption could be a bimolecular process in which a collision between one imidacloprid molecule and one adsorption site occurs. Therefore, this adsorption is chemisorption (Kumar et al., 2006; Fernandez-Bayo et al., 2008). However, the rate constant values are $3.10 \mathrm{mg} / \mathrm{g} / \mathrm{h}$ and $10.204 \mathrm{mg} / \mathrm{g} / \mathrm{h}$ for soils A and B respectively confirming thus, the relative slowness of adsorption.

\section{Modeling of adsorption isotherms}

The adsorption isotherm indicates the adsorption molecules distribution between the 
liquid phase and the solid phase when the adsorption process reaches an equilibrium state. For this study, $5 \mathrm{~g}$ of soil was mixed with $100 \mathrm{~mL}$ of different imidacloprid concentrations as $1 \mathrm{ppm}, 5 \mathrm{ppm}, 10 \mathrm{ppm}, 20$ ppm et $30 \mathrm{ppm}$ in a $250 \mathrm{ml}$ conical flasks. The reaction mixtures were shaken on magnetic agitator at $200 \mathrm{rpm}$ for equilibrium time (6 hours) at room temperature. After equilibrium, the samples were filtered and analyzed with HPLC. The amount of imidacloprid adsorbed per unit of mass of the soil at equilibrium, $q_{e}$, was calculated by:

$q_{e}=\frac{\left(c_{0}-c_{e}\right)}{m \times V}$

where $C_{0}(\mathrm{mg} / \mathrm{L})$ and $C_{\mathrm{e}}(\mathrm{mg} / \mathrm{L})$ are the concentrations of imidacloprid at initial and equilibrium times respectively, $\mathrm{V}(\mathrm{L})$ is the volume of the initial solution, and $\mathrm{m}(\mathrm{g})$ is the mass of the soil sample. .

Adsorption equilibrium data of imidacloprid on soils were fitted by applying Langmuir, Freundlich and Redlich - Peterson isotherm models, respectively.

\section{Langmuir Isotherm Model}

The expression of the Langmuir model is given by: $q_{\theta}=\frac{q_{m} b C_{\theta}}{1+b c_{\theta}}$ (3) where $q_{\theta}(\mathrm{mg} / \mathrm{g})$ and $\mathrm{C}_{e}(\mathrm{mg} / \mathrm{L})$ represent the amount of adsorbed imidacloprid per unit of mass of soil and imidacloprid concentration at equilibrium, respectively, $q_{m}(\mathrm{mg} / \mathrm{g})$ is the maximum adsorption capacity of the soil and $\mathrm{b}$ is a constant related to the affinity of binding sites.

The linear expression of Langmuir model $\frac{1}{q_{e}}=f\left(\frac{1}{c_{e}}\right)$ gives the plots of Figure 3 and parameters in Tables 4 and 5. Correlation coefficients were below 0.95 and the calculated $\mathrm{q}_{\mathrm{m}}$ were not appropriated to use as maximum capacity of imidacloprid adsorption onto these soils suggesting that the adsorption of imidacloprid did not obey Langmuir isotherm. So soils were therefore not homogeneous.

\section{Freundlich Isotherm Model}

The relation between the amount of adsorbed solute $q_{\theta} \quad(\mathrm{mg} / \mathrm{g})$ and his concentration at equilibrium $\mathrm{C}_{e}(\mathrm{mg} / \mathrm{L})$ for Freundlich adsorption isotherm is given by equation (4):

$$
q_{e=} K_{F} C_{e}{ }^{1 / n}
$$

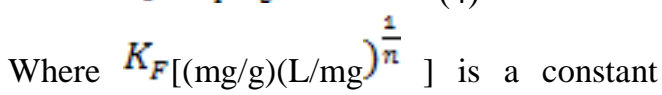
related to adsorption capacity and $\mathrm{n}$ is a measure of surface heterogeneity (Hamdaoui and Naffrechoux, 2007).

The plots of $\ln \mathrm{q}_{\mathrm{e}}=\mathrm{f}\left(\ln \mathrm{C}_{\mathrm{e}}\right)$ is given in Figure 4 and parameters of this model in Tables 4 and 5. The correlation coefficients, $\mathrm{R}^{2}$ are higher than 0.96 then, this model may obeyed the sorption of imidacloprid. The value of $\mathrm{n}$ is 1.518 and 1.439 for the soil A and B respectively. As $1<$ $\mathrm{n}<10$ suggests that the adsorption process may be favorable, so the soils are heterogeneous (Al-Mutairi, 2010).

\section{Redlich - Peterson Isotherm Model}

Redlich-Peterson isotherm is an empirical model that incorporates features of the Langmuir and the Freundlich isotherm models to represent equilibrium data by:

$$
\operatorname{Ln}\left(\frac{\mathrm{q}_{\mathrm{m}} \mathrm{K}_{\mathrm{L}} \mathrm{C}_{\Theta}}{\mathrm{q}_{\Theta}}-1\right)=\mathrm{nLnC}_{\mathrm{e}}+\operatorname{LnK}_{\mathrm{L}}
$$

Where $\mathrm{K}_{\mathrm{L}}(\mathrm{L} / \mathrm{mg})$ and $q_{m}(\mathrm{mg} / \mathrm{g})$ are constant at equilibrium of Langmuir and maximum amount of imidacloprid, respectively and $n$ like « $n$ » of Freundlich ranging from 0 to 1 (Hamdaoui and Naffrechoux, 2007).

The plots obtained by application of this model are shown in Figure 5 and model parameters are given in Tables 4 and 5. This adsorption isotherm with $\mathrm{R}^{2}>0.99$ describes better than the previous isotherms. Therefore, the adsorption of imidacloprid on both soils is less multilayer with non- uniform distribution of adsorption heat and affinities (Samiey, 2010). This can explain why these soils retain weakly imidacloprid. However, adsorption capacities of these soils are higher than those of many of soils studied by adsorption of organic pollutants onto them (Pizzutti et al., 2007; Muhammad et al., 2012). 
Table 1: Physicochemical properties of the soil.

\begin{tabular}{lcc}
\hline Soils Parameters & Banana field & Cocoa field \\
\hline $\mathrm{pH}$ & 5.33 & 5.11 \\
Electrical Conductivity $(\mu \mathrm{S} / \mathrm{cm})$ & 0.11 & 0.12 \\
Organic Matter $(\%)$ & 9.98 & 10.16 \\
Clay $(\%)$ & 2.6 & 18.18 \\
Sand $(\%)$ & 91.17 & 64.32 \\
Slit $(\%)$ & 6.23 & 27.52 \\
Classification & Sandy & Sandy Loam \\
\hline
\end{tabular}

Table 2: Recoveries, LOD and LOQ of method.

\begin{tabular}{lcc}
\hline Parameter & \multicolumn{2}{c}{ value } \\
\cline { 2 - 3 } & Soil A & Soil B \\
\hline Percent recovery $(\%)$ & $74 \% \pm 1.02$ & $81.12 \pm 1.04$ \\
LOD $(\mu \mathrm{g} / \mathrm{Kg})$ & $0.013 \pm 0.00027$ & $0.012 \pm 0.00018$ \\
LOQ $(\mu \mathrm{g} / \mathrm{Kg})$ & $0.042 \pm 0.0009$ & $0.039 \pm 0.0006$ \\
\hline
\end{tabular}

Table 3: Evolution of imidacloprid on soils.

\begin{tabular}{lcccc}
\hline Time (day) & \multicolumn{2}{c}{ Soil of cocoa field } & \multicolumn{2}{c}{ Soil of banana field } \\
\hline & $\begin{array}{c}\text { Concentration } \\
(\mathbf{m g} / \mathbf{L})\end{array}$ & $\begin{array}{c}\text { Percent of } \\
\text { remain }(\boldsymbol{\%})\end{array}$ & $\begin{array}{c}\text { Concentration } \\
(\mathbf{m g} / \mathbf{L})\end{array}$ & $\begin{array}{c}\text { Percent of } \\
\text { remain }(\boldsymbol{\%})\end{array}$ \\
\hline $1^{\text {st }}$ & 1.43125 & 0 & 1.19832 & 0 \\
$3^{\text {rd }}$ & 1.36421 & 4.68 & 1.18567 & 1.06 \\
$7^{\text {th }}$ & 1.30135 & 9.05 & 1.04007 & 13.20 \\
$10^{\text {th }}$ & 1.20136 & 16.06 & 0.89777 & 25.08 \\
$15^{\text {th }}$ & 0.93757 & 34.49 & 0.72423 & 39.56 \\
$30^{\text {th }}$ & 0.84453 & 40.99 & 0,69737 & 41.80 \\
$60^{\text {th }}$ & 0.72145 & 49.59 & 0.58668 & 51.04 \\
$90^{\text {th }}$ & 0.30456 & 78.72 & 0.21132 & 82.36 \\
\hline
\end{tabular}

Table 4: Equilibrium adsorption isotherm values for imidacloprid: a) onto soil A.

\begin{tabular}{|c|c|c|c|}
\hline Soil A & Model & Parameter & Value \\
\hline & \multirow{3}{*}{ Langmuir } & $\mathrm{q}_{\mathrm{m}}(\mathrm{mg} / \mathrm{g})$ & 13.532 \\
\hline & & $\mathrm{b}$ & 0.327 \\
\hline & & $\mathrm{R}^{2}$ & 0.9238 \\
\hline & \multirow{3}{*}{ Freundlich } & $\mathrm{K}$ & 27.816 \\
\hline & & $\mathrm{n}$ & 1.518 \\
\hline & & $\mathrm{R}^{2}$ & 0.984 \\
\hline & \multirow{4}{*}{ Redlich-Péterson } & $\mathrm{q}_{\mathrm{m}}(\mathrm{mg} / \mathrm{g})$ & 4.139 \\
\hline & & $\mathrm{K}_{\mathrm{L}}$ & 1.069 \\
\hline & & $\mathrm{n}$ & 0.364 \\
\hline & & $\mathrm{R}^{2}$ & 0.9948 \\
\hline
\end{tabular}


Table 5: Equilibrium adsorption isotherm values for imidacloprid: b) onto soil B.

\begin{tabular}{cccc}
\hline Soil B & Model & Parameter & Value \\
\hline \multirow{3}{*}{ Langmuir } & $\mathrm{q}_{\mathrm{m}}(\mathrm{mg} / \mathrm{g})$ & 14.701 \\
& $\mathrm{~b}$ & 0.340 \\
& $\mathrm{R}^{2}$ & 0.904 \\
\hline \multirow{2}{*}{ Freundlich } & $\mathrm{K}$ & 31.047 \\
& $\mathrm{n}$ & 1.439 \\
& $\mathrm{R}^{2}$ & 0.965 \\
\hline \multirow{2}{*}{ Redlich-Péterson } & $\mathrm{q}_{\mathrm{m}}(\mathrm{mg} / \mathrm{g})$ & 5.741 \\
& $\mathrm{~K}_{\mathrm{L}}$ & 1.543 \\
& $\mathrm{n}$ & 0.3587 \\
& $\mathrm{R}^{2}$ & 0.9978 \\
\hline
\end{tabular}

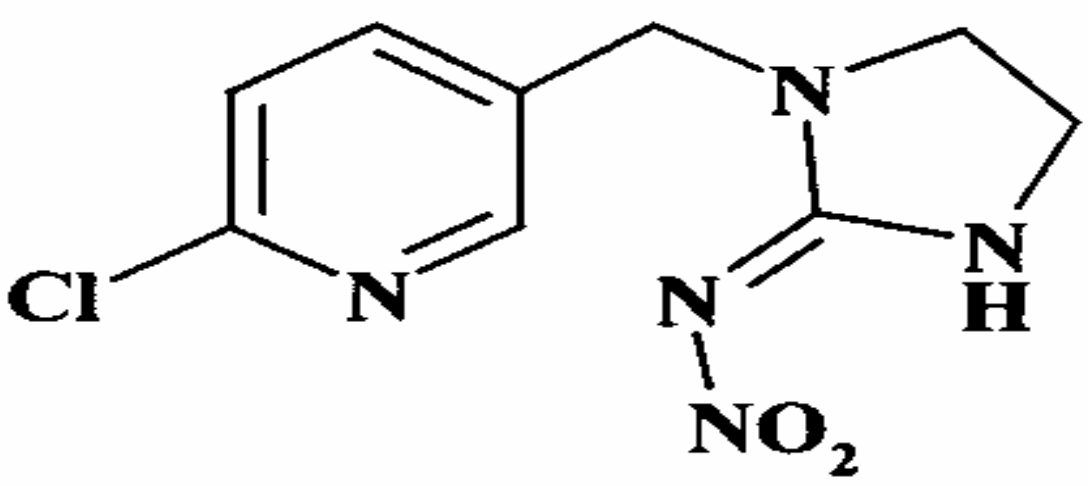

Figure 1: Chemical structure of imidacloprid.

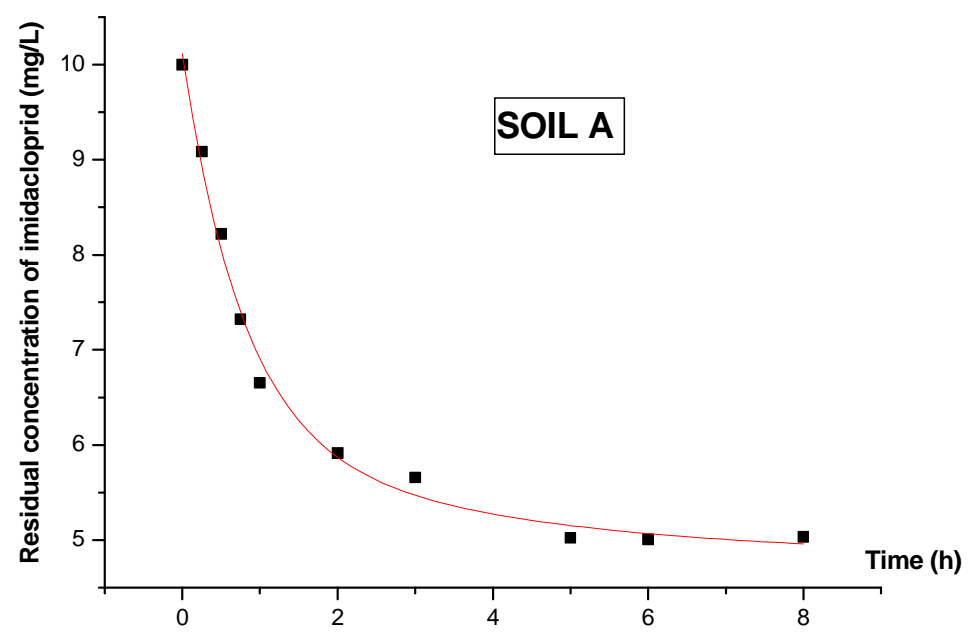




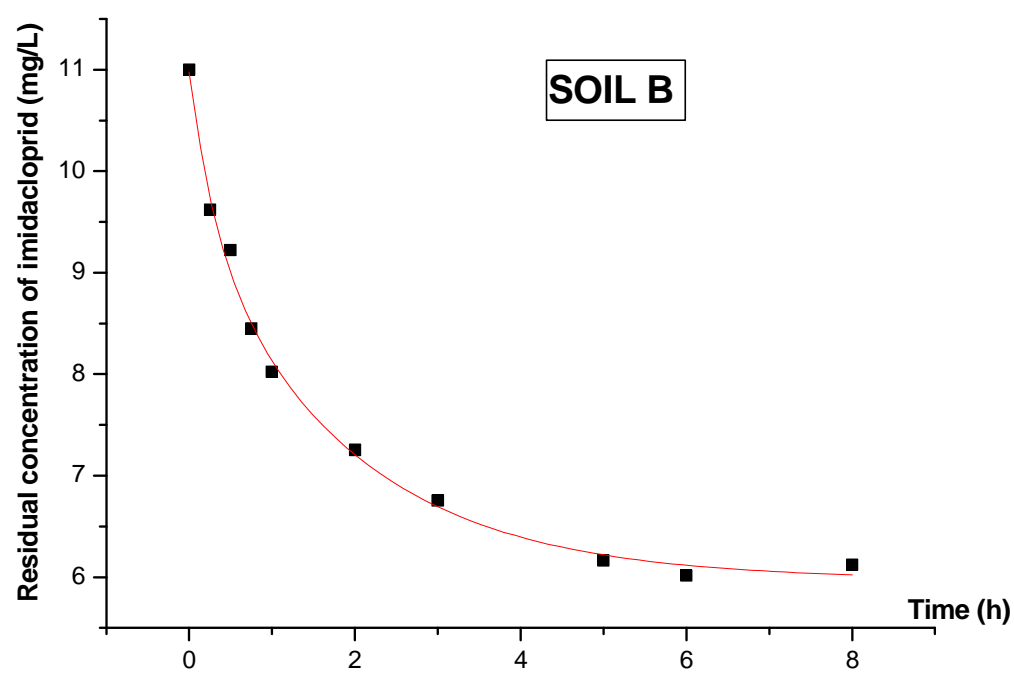

Figure 2: Adsorption kinetic of imidacloprid on soils A and B.

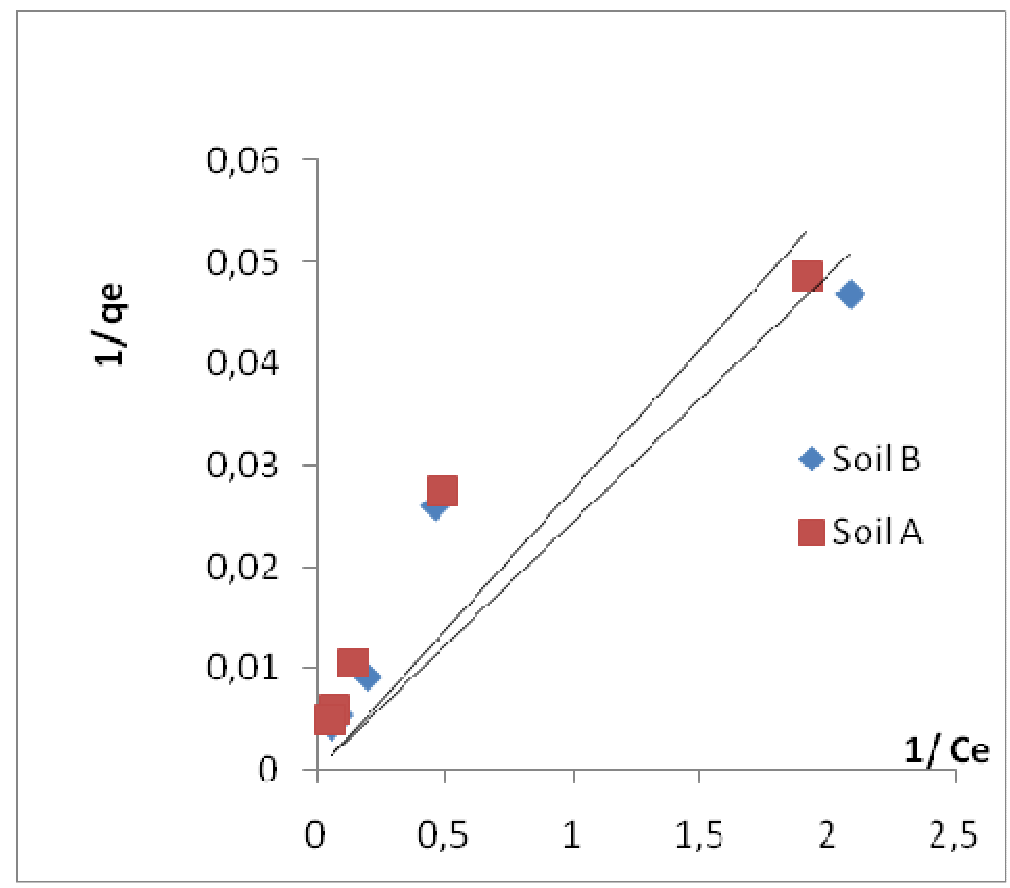

Figure 3: Linear form of Langmuir isotherm for imidacloprid adsorption on soils. 


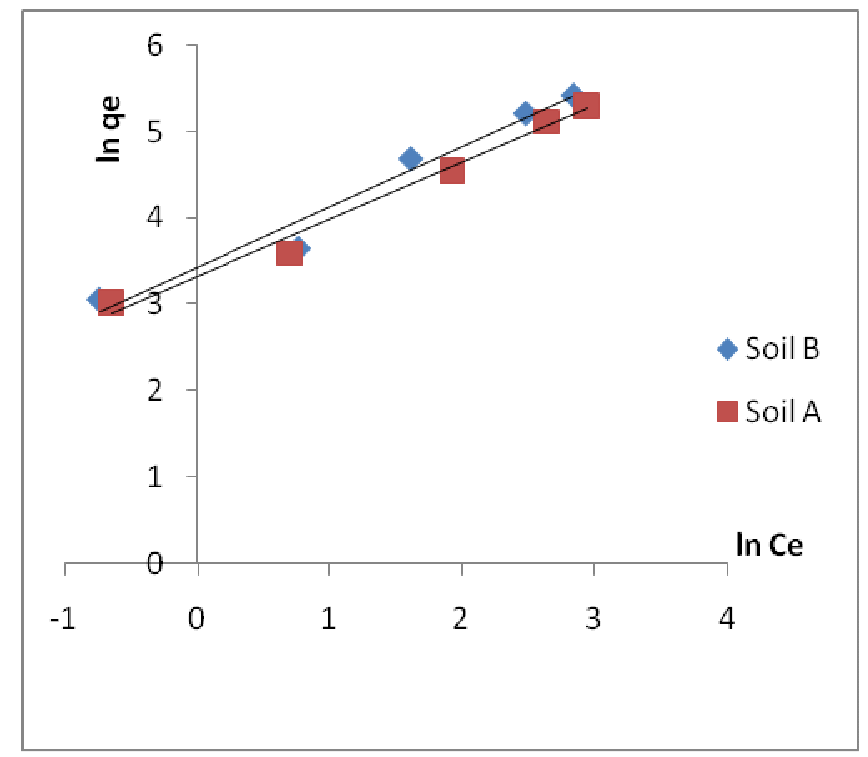

Figure 4: Linear form of Freundlich isotherm for imidacloprid adsorption on soils.

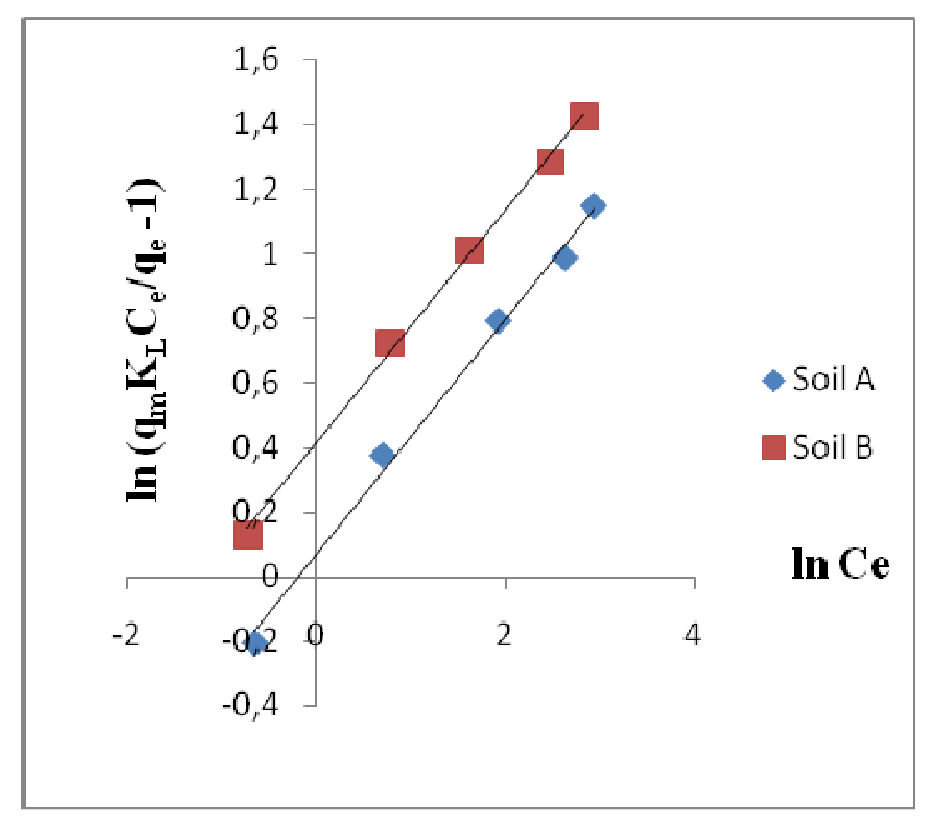

Figure 5: Linear form of Redlich-Peterson isotherm for imidacloprid adsorption on soils.

\section{Conclusion}

A very fast and easy method has been developed to determine imidacloprid onto soils using only acetonitrile as solvent. Comparison of imidacloprid adsorption performance onto two different soils revealed that adsorption isotherms are best fitted by Redlich-Peterson and Freundlich models. The adsorption processes were found to follow the pseudo-second order kinetics over a period of 6 hours. It was demonstrated that the surfaces 
of the soils are heterogeneous and adsorption process is chemisorption.

Soils have high organic matter but different textures. Due to high clay, adsorption is better onto Sandy Loam in cocoa field than Sandy in banana field. The soils do not retain very well imidacloprid and may be potential candidates against diffusion or significant leaching.

\section{REFERENCES}

Al-Mutairi NZ. 2010. 2,4-Dinitrophenol adsorption by date seeds: Effect of physico-chemical environment and regeneration study. Desalination, 250(3): 892-901.

Ayranci E, Hoda N. 2004. Adsorption of bentazon and propanil from aqueoussolutions at the high area activated carbon-cloth. Chemosphere, 57(8): 755-762.

Ben Hassine H. 2006. Nature minéralogique et rôle nutritionnel des argiles de sols céréaliers en région subhumide à semiaride (Tunisie). C. R. Géoscience, 338(5): 329-340.

Bonmatin JM, Marchand P, Charvet R, Moineau I, Bengsch E. 2005. Quantification of imidacloprid uptake in maize crops. J. Agric. Food Chem., 53(13): 5336-5341.

Carvalho FP. 2006. Agriculture, pesticides, food security and food safety. Environ Sci Policy, 9(7-8): 685-692.

Charvet R, Katouzian-Safadi M, Colin M, Marchand P, Bonmatin J. 2004. Systemic insecticides new risk for pollinator insects. Ann. Pharm. Fr., 62(1): 29-35.

Concha-Grañan E, Fernández-González V, Grueiro-Noche G, Muniategui-Lorenzo S, López-Mahía P, Fernández-Fernández E, Prada-Rodríguez D. 2010. Development of an environmental friendly method for the analysis of organochlorine pesticides in sediments. Chemosphere, 79(7): 698705.

CCEM (Conseil canadien des ministres de l'environnement). $2007 . \quad$ Fiche d'information. Recommandations canadiennes pour la qualité des eaux : protection de la vie aquatique imidaclopride, report 1300, CCEM.

FAO. 2012. Undernourishment around the world in 2012. The state of food in security in the world.

Fernandez-Bayo JD, Nogales R, Romero E. 2008. Evaluation of the sorption process for imidacloprid and diuron in eight agricultural soils from Southern Europe using various kinetic models. J. Agric. Food Chem., 56(13): 5266-5272.

Giroux I. 2003. Contamination de l'eau souterraine par les pesticides et les nitrates dans les régions en culture de pommes de terre. Campagne d'échantillonnage de 1999-2000-2001. Direction du suivi de l'état de l'environnement, ministère de l'Environnement, Gouvernement du Québec.

Hamdaoui O, Naffrechoux E. 2007. Modeling of adsorption isotherms of phenol and chlorophenols onto granular activated carbon. J. Hazard. Mater., 147(1): 401411.

Kumar M, Philip L. 2006. Adsorption and Desorption Characteristics of Hydrophobic Pesticide Endosulfan in Four Indian Soils. Chemosphere, 62(7): 1064-1077.

Madrigal-Monarez I. 2004. Rétention de pesticides dans les sols des dispositifs tampon, enherbés et boisés. Rôle des matières organiques. Thèse, Institut Agronomique Paris Grignon, Paris, p. 15.

Margni M, Rossier D, Crettaz P, Jolliet O. 2002. Life cycle impact assessment of pesticides on human health and ecosystems. Agric., Ecosys. Environ., 93(1): 379-392.

Melo LFC, Collins CH, JardimICSF. 2005. High-performance liquid chromatographic determination of pesticides in tomatoes using laboratory-made $\mathrm{NH} 2$ and $\mathrm{C}_{18}$ solid-phase extraction materials. $J$. Chromatography A, 1073(1-2): 75-81.

Ministère de l'Agriculture de Côte D'ivoireISYSPHYT.CI. 2012. Liste actualisée des pesticides homologués et autorisés en 
Côte d'Ivoire 31 Décembre 2012. www.ISYSPHYT.CI.

Moreno MT, Audesse P, Giroux M, Frenette N, Cescas M. 2001. Comparaison entre la détermination de la matière organique des sols par la méthode de Walkley-Black et la méthode de perte au feu. Agrosol, 12(1): 49-58.

Muhammad AB, Shafi MN, Sherazi ST, Muhammad IB. 2012. Adsorption and leaching potential of imidacloprid pesticide through alluvial soil. Am. J. Analy. Chem., 3(8): 604-611.

Papiernik SK, Koskinen WC, Cox L, Rice PJ, Clay SA, Werdin-Pfisterer NR, Norberg K. 2006. Sorption- desorption of imidacloprid and its metabolites in soil and vadose zone materials. J. Agric. Food Chem., 54(21): 8163-8170.

Paszko T. 2006. Sorptive behavior and kinetics of carben-dazim in mineral soils. Polish J. Environ. Studi., 15(3): 449-456.

Perrier A, Tuzet A, 2005. Le cycle de l'eau et les activités au sein de l'espace rural. Enjeux globaux, solutions locales et régionales. C. R. Géoscience, 337(1): 3956.

Ping L, Zhang C, Zhu Y, Wu M, Dai F, Hu X, Zhao H, Li Z. 2010. Imidacloprid adsorption by soils treated with humic substances under different $\mathrm{pH}$ and temperature conditions. Afric. J. Biotechnol., 9(13):1935-1940.

Pizzutti IR, de Kok A, Zanella R, Adaimea MB, Hiemstra M, Wickert C, Prestes OD. 2007. Method validation for the analysis of 169 pesticides in soya grain, without clean up, by liquid chromatographytandem mass spectrometry using positive and negative electrospray ionization. $J$. Chromatogra. A, 1142(2): 123-136.

Sabbagh GJ, Lenz MF, Fisher JM, Arthur EL. 2002. Significance of binding on imidacloprid degradation in soils, and effects of soil characteristics on imidacloprid adsorption capacity. Report 200327, Bayer CropSci.

Samiey B, Dargahi M. 2010. Kinetics and thermodynamics of adsorption of Congo red on cellulose. Central Eur. J. Chem., 8(4): 906-912.

Sheng G, Jhonston CT, Teppen BJ, Boyds A. 2001.Potential contributions of smectites clays and organic matter to pesticide retention in soils. J. Agric. Food Chem., 49: 2899-2970.

Shrivastava A, Gupta VP. 2011. Methods for the determination of limit of detection and limit of quantitation of the analytical methods. Chronicles of Young Scientists, 2(1): 21-25.

Stokstad E. 2012. Field Research on Bees Raises Concern About Low-Dose Pesticides. Science, 335(6076): 15331660.

Walorczyk S. 2008. Development of a multiresiduemethod for the determination of pesticides in cereals and dry animal feedusinggaschromatography-tandem quadrupole mass spectrometry II. Improvement and extension to new analytes. J. Chromatogra. A, 1208(1-2): 202-214. 